\title{
Article \\ Changes in Daily Life Satisfaction among Community Dwelling Elderly during the COVID-19 Pandemic in Japan
}

\author{
Akira Ishida ${ }^{1, *(\mathbb{D})}$ and Emiko Ishida ${ }^{2}$ \\ 1 Graduate School of Agricultural Science, Kobe University, 1-1 Rokkodai, Nada-ku, Kobe 657-8501, Japan \\ 2 School of Nursing, Hyogo University of Health Sciences, 1-3-6 Minatojima, Chuo-ku, Kobe 650-8530, Japan; \\ ei-ishida@huhs.ac.jp \\ * Correspondence: akira_ishida@people.kobe-u.ac.jp; Tel.: +81-78-803-5844
}

Citation: Ishida, A.; Ishida, E.

Changes in Daily Life Satisfaction among Community Dwelling Elderly during the COVID-19 Pandemic in Japan. J. Ageing Longev. 2021, 1, 3-10. https://doi.org/10.3390/jal1010002

Academic Editor: Mark A. Tully

Received: 23 June 2021

Accepted: 22 July 2021

Published: 10 August 2021

Publisher's Note: MDPI stays neutral with regard to jurisdictional claims in published maps and institutional affiliations.

Copyright: (c) 2021 by the authors. Licensee MDPI, Basel, Switzerland. This article is an open access article distributed under the terms and conditions of the Creative Commons Attribution (CC BY) license (https:// creativecommons.org/licenses/by/ $4.0 /)$.

\begin{abstract}
Previous studies pointed out that the outbreak of the coronavirus disease 2019 (COVID-19) had a lesser effect on elderly people compared to their younger counterparts. However, a limited number of studies have analyzed the effects of COVID-19 on the psychological aspects of the elderly using longitudinal data. Therefore, the main objective of our study was to clarify the changes in self-rated overall daily life satisfaction among community dwelling elderly in Japan during the COVID-19 pandemic. We used the longitudinal data of 5176 individuals aged 15 years and older from the first and second internet surveys on "Changes in Daily Life Awareness and Behavior under the Influence of the New Coronavirus Infection" conducted by the Cabinet Office of Japan. The estimation result of the mixed-effects model indicated that elderly people were more adversely affected by the first wave of the pandemic (May 2020) compared to their younger counterparts. However, by the beginning of the third wave (December 2020), they had largely recovered to the same level as that of before the COVID-19 pandemic, which suggested that the elderly managed to cope with psychological distress to some extent during the prolonged COVID-19 pandemic.
\end{abstract}

Keywords: COVID-19; Japan; life satisfaction

\section{Introduction}

Since the emergence of the coronavirus disease 2019 (COVID-19) in December 2019 in China, the infectious disease has rapidly spread to many other countries, regardless of their economic levels. Consequently, the World Health Organization (WHO) declared the outbreak of COVID-19 as a global pandemic on 11 March 2020. A state of emergency was declared in many countries where preventive measures were taken not only to encourage the public to stay at home and practice social distancing, but also to limit public gatherings, suspend events with audiences, and/or lockdown cities in the worst case. This was also the case in Japan. When the number of people infected with COVID-19 increased towards the end of March and beginning of April 2020, the first state of emergency related to COVID-19 was declared in the most densely populated Kanto region (Tokyo, Kanagawa, Saitama, and Chiba), Kansai region (Osaka and Hyogo), and Fukuoka on 7 April 2020, and was extended nationwide on 16 April 2020. Although the first state of emergency was fully lifted on 25 May 2020, the government declared a state of emergency again to cope with the third wave on 8 January 2021.

The COVID-19 pandemic has caused negative effects on the psychosocial aspects of the elderly, such as increased feelings of anxiety [1], loneliness [2], and lower levels of mental well-being [1]. Previous studies pointed out that the outbreak had a lesser effect on older people compared to their younger counterparts in the USA [3], the UK [4], Germany and Poland [5], Spain [6,7], Israel [8], and Japan [9], even though they were at greater risk of fatality from COVID-19.

However, a limited number of studies have analyzed the effects of COVID-19 on the psychological aspects of the elderly using longitudinal data. This is the case in Japan. Since 
the country is a super-aged society with the proportion of people aged 65 or older being the highest in the world, maintaining or improving well-being and mitigating the anxiety of the elderly have always been high on the agenda of social welfare policy. Therefore, our main objective was to clarify the changes in self-rated overall daily life satisfaction among community-dwelling elderly in Japan during the COVID-19 pandemic, using longitudinal data. Our insights into the changes in daily life satisfaction among the elderly during the COVID-19 pandemic may provide policy makers and practitioners with useful information not only in Japan, but also in other rapidly aging countries such as several European and Asian countries. To the best of our knowledge, a limited number of studies have analyzed the trajectory changes in the psychological aspects of the elderly.

\section{Materials and Methods}

The Cabinet Office of Japan conducted the first and second internet surveys on "Changes in Daily Life Awareness and Behavior under the Influence of the New Coronavirus Infection" after the end of the first wave of COVID-19 (from 25 May to 5 June 2020) and at the beginning of the third wave (from 11 to 17 December 2020). In the first survey, 10,128 people aged 15 years and older, who were assigned according to the population ratio of the seven districts in Japan, responded. Of these, 5212 people also responded to the second survey. All respondents were pre-registered monitors of a web-based market survey company.

In the first survey, all respondents were asked to answer the extent of their overall satisfaction with daily life at two points in time (before the spread of COVID-19 and just after the end of the first wave). They were asked to answer in one-point units, with "not at all satisfied" which was scored as 0 and "very satisfied" which was scored as 10 . In the second survey, 5212 people who participated in the first survey also replied to the question regarding daily life satisfaction at the beginning of the third wave, which meant that three time-point longitudinal data were available for analysis. Therefore, we applied the mixed-effects model to the longitudinal data from 5176 individuals who responded to all the necessary questions from both surveys, and compared how the life satisfaction of the elderly changed compared to middle-aged and younger counterparts at three time points: before the COVID-19 pandemic, immediately after the end of the first wave (May 2020), and at the beginning of the third wave (December 2020).

After a lack of multicollinearity was confirmed between the independent variables, the following categories were formulated via dummy-coded variables for gender (male and female), age of the cohort at the time of the first survey (15-24, 25-34, 35-44, 45-54, 55-64, 65-74, and $\geq 75$ years old), the time at which respondents answered the level of overall daily life satisfaction (before COVID-19 pandemic, end of the first wave (May 2020), and beginning of the third wave (December 2020)), cohabitation (single and living with family), and the region (prefectures with low numbers of infected people and prefectures with high numbers of infected people, such as Hokkaido, Kanto region including Tokyo, Chiba, Kanagawa, and Saitama, and Kinki region such as Kyoto, Osaka, and Hyogo). In addition to the abovementioned variables, cross terms of the variable for the time at which respondents answered the satisfaction level and one of the other dependent variables such as gender, age cohort, cohabitation, and region were also used as independent variables.

All data were analyzed with STATA version 16.1, using 95\% confidence intervals (CIs) and a significance level of 0.05 .

\section{Results}

\subsection{Subjects' Characteristics}

The frequency of each independent variable is shown in Table 1. Of the 5176 respondents, 2549 were male $(49.2 \%)$ and 2627 were female $(50.8 \%)$. As for the age structure, the 15-24 age cohort accounted for $11.5 \%$, 25-34 for $17.0 \%$, 35-44 for $17.7 \%, 45-54$ for $17.8 \%$, 55-64 for $17.9 \%$, 65-74 for $15.1 \%$, and 75 and older for $2.9 \%$ (only the data for age cohort were provided by the Cabinet Office due to protection of the respondents' privacy). As 
for cohabitation status, $18.1 \%$ of the respondents lived alone, and $81.9 \%$ lived with family. Approximately $61.7 \%$ lived in the Hokkaido, Kanto, and Kinki regions which were more affected by COVID-19 and the remaining 38.3\% lived in other regions.

Table 1. Subject characteristics.

\begin{tabular}{lcc}
\hline \multicolumn{1}{c}{ Characteristics } & Total $\mathbf{5 1 7 6}$ \\
\hline Gender & & \\
Male & 2549 & $(49.2)$ \\
Female & 2627 & $(50.8)$ \\
\hline Age cohort & & \\
15-24 age & 597 & $(11.5)$ \\
25-34 age & 881 & $(17.0)$ \\
35-44 age & 918 & $(17.7)$ \\
45-54 age & 922 & $(17.8)$ \\
55-64 age & 928 & $(15.9)$ \\
65-74 age & 780 & $(2.9)$ \\
75+ age & 150 & $(18.1)$ \\
Cohabitation & & $(81.9)$ \\
Single & 938 & \\
Cohabitated & 4238 & $(61.7)$ \\
Hokkaido + Kanto + Kinki & & $(38.3)$ \\
\hline Other prefectures & 3193 & \\
\hline
\end{tabular}

Source: Calculated by authors.

We compared the mean score of the overall daily life satisfaction for all respondents at the three points time and found that it decreased from $5.95 \pm 2.28$ (before the pandemic) to $4.46 \pm 2.27$ (just after the first wave), but increased to $5.62 \pm 2.31$ (at the initial stage of the third wave) (Table 2). As for the mean score for those aged 15 and 64, it dropped from $5.84 \pm 2.29$ to $4.43 \pm 2.30$, and bounced back to $5.46 \pm 2.33$. The score for those aged 65 years and older varied from $6.46 \pm 2.15$ to $4.56 \pm 2.11$ and $6.35 \pm 2.03$, which suggested that although a similar V-shaped trajectory was found, the extent of the changes in the overall daily life satisfaction during the COVID-19 pandemic seemed larger for the elderly.

Table 2. Changes in mean scores of overall daily life satisfaction by age cohort.

\begin{tabular}{cccccccc}
\hline \multirow{2}{*}{$\begin{array}{c}\text { Age } \\
\text { Cohort }\end{array}$} & \multicolumn{2}{c}{ Before the Pandemic } & \multicolumn{2}{c}{$\begin{array}{c}\text { After the 1st Wave } \\
\text { (May 2020) }\end{array}$} & \multicolumn{2}{c}{$\begin{array}{c}\text { Beginning of the 3rd } \\
\text { Wave (December 2020) }\end{array}$} & \multirow{2}{*}{ N } \\
\cline { 2 - 6 } & Mean & s.d. & Mean & s.d. & Mean & s.d. & \\
\hline $15-24$ & 6.09 & 2.19 & 4.64 & 2.30 & 5.40 & 2.14 & 597 \\
$25-34$ & 5.94 & 2.13 & 4.59 & 2.28 & 5.33 & 2.24 & 881 \\
$35-44$ & 5.82 & 2.37 & 4.48 & 2.39 & 5.52 & 2.43 & 918 \\
$45-54$ & 5.56 & 2.41 & 4.22 & 2.25 & 5.31 & 2.40 & 922 \\
$55-64$ & 5.90 & 2.28 & 4.32 & 2.26 & 5.73 & 2.36 & 928 \\
$65-74$ & 6.43 & 2.17 & 4.58 & 2.10 & 6.33 & 2.02 & 780 \\
$75+$ & 6.63 & 2.06 & 4.48 & 2.16 & 6.47 & 2.07 & 150 \\
Subtotal & & & & & & & \\
$15-64$ & 5.84 & 2.29 & 4.43 & 2.30 & 5.46 & 2.33 & 4246 \\
$65+$ & 6.46 & 2.15 & 4.56 & 2.11 & 6.35 & 2.03 & 930 \\
All & 5.95 & 2.28 & 4.46 & 2.27 & 5.62 & 2.31 & 5176 \\
\hline
\end{tabular}

Source: Calculated by authors.

\subsection{Estimation Results}

The estimation results of the mixed-effects model are shown in Table 3. Of the 29 coefficients of independent variables or their cross terms, 19 coefficients were significant at the $1 \%$ or $5 \%$ levels. The null hypothesis that all coefficients were equal to zero was rejected 
by the Wald test at the $1 \%$ level (a chi-square test statistic with 29 degrees of freedom was 2365.91), which indicated that the model was fitted well to the data. Both between-subject and within-subject variances (2.00 and 3.11, respectively) were found to be significant at the $1 \%$ level, and the latter value was larger than that of the former.

Table 3. Estimation results of overall daily life satisfaction by the mixed-effects model.

\begin{tabular}{|c|c|c|c|c|c|}
\hline Fixed Effects & Coefficient & s.e. & & & \\
\hline Female & 0.30 & 0.06 & $* *$ & 0.17 & 0.42 \\
\hline $\begin{array}{l}\text { COVID-19 (reference: before COVID-19 pandemic) } \\
\text { end of the 1st wave (May 2020) } \\
\text { beginning of the 3rd wave (December 2020) }\end{array}$ & $\begin{array}{l}-1.00 \\
-0.56\end{array}$ & $\begin{array}{l}0.13 \\
0.13\end{array}$ & $* *$ & $\begin{array}{l}-1.26 \\
-0.83\end{array}$ & $\begin{array}{l}-0.74 \\
-0.30\end{array}$ \\
\hline $\begin{array}{l}\text { gender } \times \text { COVID-19 } \\
\text { female } \times \text { end of the } 1 \text { st wave } \\
\text { female } \times \text { beginning of the } 3 \text { rd wave }\end{array}$ & $\begin{array}{l}-0.47 \\
-0.22\end{array}$ & $\begin{array}{l}0.07 \\
0.07\end{array}$ & $* *$ & $\begin{array}{l}-0.61 \\
-0.36\end{array}$ & $\begin{array}{l}-0.34 \\
-0.09\end{array}$ \\
\hline $\begin{array}{l}\text { age cohort (reference: } 15-24 \text { age) } \\
\text { 25-34 age } \\
35-44 \text { age } \\
45-54 \text { age } \\
55-64 \text { age } \\
65-74 \text { age } \\
75+\text { age }\end{array}$ & $\begin{array}{l}-0.17 \\
-0.33 \\
-0.58 \\
-0.25 \\
0.29 \\
0.49\end{array}$ & $\begin{array}{l}0.12 \\
0.12 \\
0.12 \\
0.12 \\
0.12 \\
0.21\end{array}$ & $\begin{array}{l}* * \\
* * \\
* \\
* \\
*\end{array}$ & $\begin{array}{c}-0.41 \\
-0.56 \\
-0.81 \\
-0.48 \\
0.04 \\
0.09\end{array}$ & $\begin{array}{c}0.06 \\
-0.09 \\
-0.34 \\
-0.01 \\
0.53 \\
0.90\end{array}$ \\
\hline $\begin{array}{l}\text { age cohort } \times \text { COVID-19 } \\
25-34 \text { age } \times \text { end of the } 1 \text { st wave } \\
25-34 \text { age } \times \text { beginning of the } 3 \text { rd wave } \\
35-44 \text { age } \times \text { end of the } 1 \text { st wave } \\
\text { 35-44 age } \times \text { beginning of the } 3 \text { rd wave } \\
45-54 \text { age } \times \text { end of the } 1 \text { st wave } \\
45-54 \text { age } \times \text { beginning of the } 3 \text { rd wave } \\
55-64 \text { age } \times \text { end of the } 1 \text { st wave } \\
55-64 \text { age } \times \text { beginning of the 3rd wave } \\
65-74 \text { age } \times \text { end of the } 1 \text { st wave } \\
65-74 \text { age } \times \text { beginning of the } 3 \text { rd wave } \\
75+\text { age } \times \text { end of the } 1 \text { st wave } \\
75+\text { age } \times \text { beginning of the 3rd wave }\end{array}$ & $\begin{array}{c}0.09 \\
0.08 \\
0.12 \\
0.38 \\
0.11 \\
0.44 \\
-0.12 \\
0.51 \\
-0.40 \\
0.58 \\
-0.69 \\
0.52\end{array}$ & $\begin{array}{l}0.13 \\
0.13 \\
0.13 \\
0.13 \\
0.13 \\
0.13 \\
0.13 \\
0.13 \\
0.14 \\
0.14 \\
0.23 \\
0.23\end{array}$ & $\begin{array}{l}\text { } \\
* * \\
* * \\
* * \\
* * \\
* * \\
* * \\
*\end{array}$ & $\begin{array}{c}-0.17 \\
-0.18 \\
-0.14 \\
0.12 \\
-0.15 \\
0.18 \\
-0.38 \\
0.26 \\
-0.66 \\
0.31 \\
-1.14 \\
0.07\end{array}$ & $\begin{array}{c}0.35 \\
0.34 \\
0.38 \\
0.64 \\
0.37 \\
0.69 \\
0.13 \\
0.77 \\
-0.13 \\
0.85 \\
-0.25 \\
0.97\end{array}$ \\
\hline $\begin{array}{l}\text { cohabitation (reference: single) } \\
\quad \text { cohabitated }(\text { cohabitated }=1, \text { single }=0)\end{array}$ & 0.43 & 0.08 & $* *$ & 0.27 & 0.59 \\
\hline $\begin{array}{l}\text { cohabitation } \times \text { COVID-19 } \\
\text { cohabitated } \times \text { end of the 1st wave } \\
\text { cohabitated } \times \text { beginning of the 3rd wave }\end{array}$ & $\begin{array}{l}-0.21 \\
-0.05\end{array}$ & $\begin{array}{l}0.09 \\
0.09\end{array}$ & * & $\begin{array}{l}-0.39 \\
-0.22\end{array}$ & $\begin{array}{c}-0.04 \\
0.13\end{array}$ \\
\hline $\begin{array}{l}\text { region (prefectures with low numbers of infected people }=0 \text { ) } \\
\text { Hokkaido }+ \text { Kanto }+ \text { Kinki }\end{array}$ & 0.10 & 0.06 & & -0.03 & 0.22 \\
\hline $\begin{array}{l}\text { region } \times \text { COVID }-19 \\
\text { Hokkaido }+ \text { Kanto }+ \text { Kinki } \times \text { end of the } 1 \text { st wave } \\
\text { Hokkaido }+ \text { Kanto }+ \text { Kinki } \times \text { beginning of the } 3 \text { rd wave } \\
\text { Constant }\end{array}$ & $\begin{array}{l}-0.06 \\
0.05 \\
5.57\end{array}$ & $\begin{array}{l}0.07 \\
0.07 \\
0.12\end{array}$ & $* *$ & $\begin{array}{c}-0.20 \\
-0.09 \\
5.33\end{array}$ & $\begin{array}{l}0.08 \\
0.19 \\
5.81\end{array}$ \\
\hline $\begin{array}{l}\text { random-effects parameters } \\
\quad \text { between-subject variance } \\
\text { within-subject variance } \\
\text { Wald test (chi-square test statistic with } 29 \mathrm{df} \text { ) }\end{array}$ & $\begin{array}{l}2.00 \\
3.11 \\
236\end{array}$ & $\begin{array}{l}0.06 \\
0.04\end{array}$ & & $\begin{array}{l}1.88 \\
3.03\end{array}$ & $\begin{array}{l}2.12 \\
3.19\end{array}$ \\
\hline
\end{tabular}

Note: The dependent variable is overall daily life satisfaction, taking values from 0 (not at all satisfied) to 10 (very satisfied). ${ }^{* *}$ and ${ }^{*}$ denote significant at $1 \%$ and $5 \%$ levels, respectively. Source: Calculated by authors.

Table 3 clearly shows that, given other conditions being the same, life satisfaction deteriorated by -1.00 points just after the end of the first wave and by -0.56 points at the 
beginning of the third wave, compared to the time before the pandemic. This suggests that, although the negative effects of the pandemic on daily life satisfaction could be mitigated just after the first wave and the beginning of the third wave, life satisfaction did not fully recover to the pre-pandemic level at the beginning of the third wave. As for gender, given other conditions being the same, women's daily life satisfaction was significantly higher than men's by 0.30 points. However, the interaction variables between dummies for gender and COVID-19 were significant with negative coefficients $(-0.47$ and -0.22 points, respectively), which suggests that females had lower life satisfaction than their male counterparts during the pandemic.

As for the relationship between age and life satisfaction, given other conditions including the effects of the COVID-19 pandemic, compared to the 15-24 age cohort, the 65-74 and $75+$ age cohorts were found to have a higher levels of life satisfaction by 0.29 and 0.49 points, respectively. However, the estimation results of the interaction variables between dummies for age and COVID-19 showed that, just after the first wave, the coefficients for the 65-74 and $75+$ age cohorts were significantly negative at -0.40 , and -0.69 points, respectively, while the coefficients for other age cohorts were insignificant, which indicates that elderly people were more adversely affected in the first wave of the pandemic. However, between just after the first wave and the initial stage of the third wave, the life satisfaction of the 65-74 and $75+$ age cohorts significantly recovered by 0.58 and 0.52 points, respectively.

As for the relationship between cohabitation and life satisfaction, respondents who cohabitated with family members had a 0.43 point higher life satisfaction than those who lived alone. However, their life satisfaction decreased by -0.21 points in the end of the first wave. Living in a prefecture of Hokkaido, Kanto or Kinki regions which were more affected by COVID-19 did not affect life satisfaction significantly.

Figure 1 compares the extent of changes in predicted scores of daily life satisfaction by age cohort at three time points, separately for men and women. Irrespective of gender, for the 15-24, 25-34, 35-44, and 45-54 age cohorts, differences between the predicted scores before the first wave and those during the initial stage of the third wave were greater for the younger age cohort, suggesting that the daily life satisfaction had not fully recovered for younger generation. Additionally, although daily life satisfaction had fully recovered for elderly males in the 65-74 and 75+ age cohorts, it had not for the female counterparts.

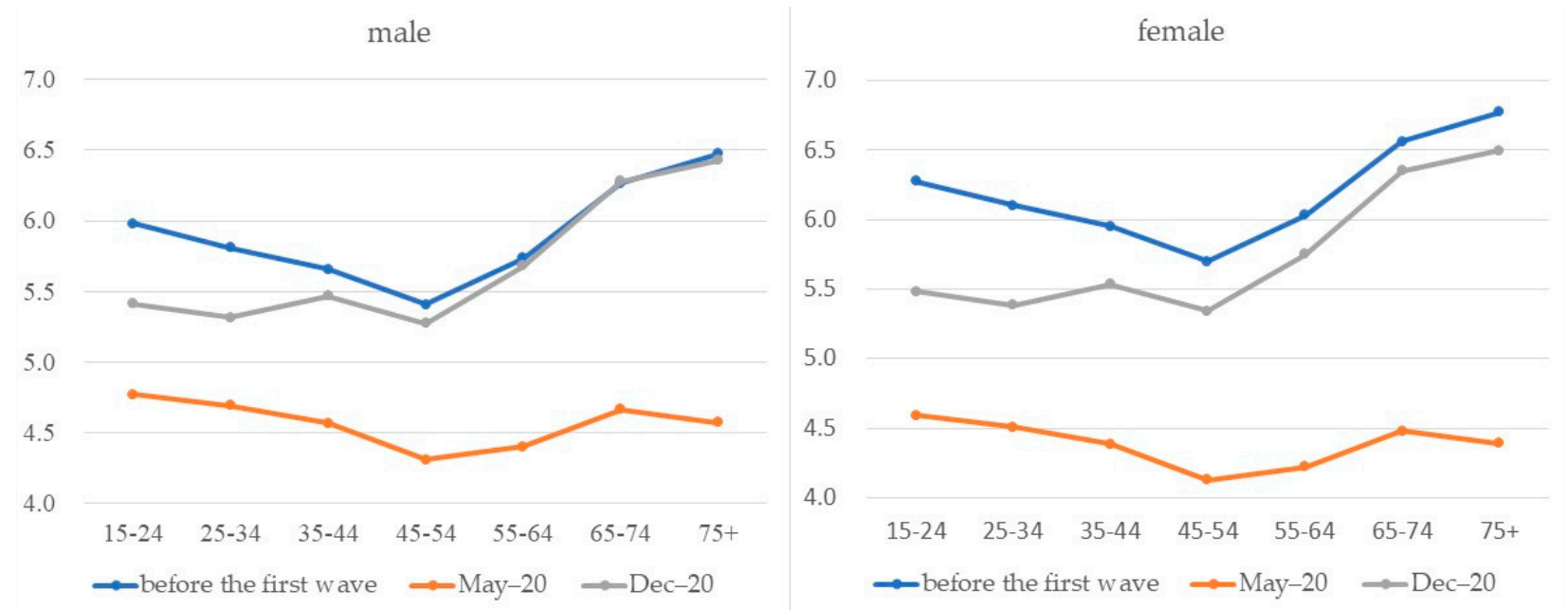

Figure 1. Predicted overall daily life satisfaction scores by gender and age cohort at three time points.

\section{Discussion}

In Japan, the COVID-19 vaccination program was started for healthcare workers around mid-February 2021 [10]. It was expanded to those aged 65 years or older and 18 and older in mid-April and mid-June 2021, respectively [11,12]. The surveys were conducted in May and December 2020 (before the vaccination program began). Therefore, 
almost none of the respondents were vaccinated, and the government vaccination program did not affect the overall daily life satisfaction of the respondents at the time of the surveys.

The estimation results showed that the life satisfaction scores were significantly decreased by COVID-19 for all age cohorts. However, elderly people in particular were more adversely affected in the first wave of the pandemic. Due to multiple infections in nursing homes for the elderly, the total number of infected people aged 60 years and over as of May 2020 accounted for approximately $40 \%$ of the total infections [13]. Through a comparison of the ratio of the number of deaths to the number of positive cases by age group, it was reported that the ratio was less than $0.5 \%$ for those in their 50 s or younger, but approximately $5 \%$ for those in their $70 \mathrm{~s}$, and more than $10 \%$ for those in their $80 \mathrm{~s}$, with the ratio increasing with age [13]. Television, newspaper, and internet reports widely circulated that while younger people were less likely to be severely infected with COVID-19 and often remained asymptomatic, elderly people were the most vulnerable high-risk population with fatalities from a very early stage. This situation may have resulted in a significant increase in psychological distress among the elderly during the first wave of the pandemic.

However, the life satisfaction of the 65-74 and 75+ age cohorts significantly recovered just after the first wave and during the beginning of the third wave. Ueda et al. [14] reported that the mental health conditions of part-time or temporary contract-based workers were the worst during the pandemic in Japan. With prolonged periods of self-restraint, the pandemic had a negative impact on job opportunities in the Japanese economy, causing working or self-employed young and middle-aged people and their households to become economically stagnant. It is also likely that the closure of schools, increase in online lectures, and decrease in the frequency of contact with friends caused mental distress among students in their teens and twenties. An increase in telework and a decrease in the frequency of contact with colleagues or friends also resulted in more stressful feelings in young and middle-aged workers. Parents, most of whom are young or middle-aged, faced an increased psychological burden of caring for their school children at home and may have been stressed due school closures. Alternatively, elderly people who rely mainly on pensions may be less economically affected. Furthermore, as pointed out by previous studies [3,5-8], elderly people were more likely to have risk tolerance, be emotionally stable, and adapt well to countermeasures against COVID-19 such as social distancing, staying at home, quarantine, and lockdown. Therefore, they may feel less psychological distress and thereby have a higher self-rated quality of life compared to their younger counterparts during the prolonged COVID-19 pandemic.

Here, it should be noted that although daily life satisfaction had fully recovered in elderly males in the 65-74 and 75+ age cohorts, this was not the case for their female counterparts. Our estimation results also showed that females were more negatively affected by the COVID-19 pandemic than their male counterparts in terms of daily life satisfaction, which was consistent with previous studies [7,9,15]. Several studies [16-18] have pointed out that Japanese elderly females, who engaged more in personal activities such as interacting with neighbors, visiting friends and relatives nearby, domestic traveling, participating in collective activities, and engaging in physical exercise, were more likely to have greater life satisfaction, whereas their male counterparts were not. Several internet-based surveys revealed that physical activity [19], socialization with friends and neighbors [20], and outings [20,21] decreased in frequency and quantity, which meant that social distancing and staying at home under the pandemic prevented elderly people from engaging in personal activities. This may have more likely negatively affected the daily life satisfaction in elderly females.

It should be noted here that geriatric studies in Japan have pointed out that physical activity, social interaction with friends or others, and outings were crucial in preventing depression [22], functional decline [23], cognitive decline [24], and dementia [25]. The fact that the life satisfaction scores of the 65-74 and 75+ age cohorts significantly recovered just after the first wave and during the initial stage of the third wave does not necessarily mean that the negative effects of social distancing and staying at home on functional, cognitive, 
and mental aspects were eliminated. Therefore, the government should carefully monitor the physical and mental health conditions of the elderly to prevent frailty among them.

This study has several limitations. First, the main limitation was that we used a single variable regarding self-rated overall daily life satisfaction to measure the effects of the COVID-19 pandemic on the psychological aspects of the elderly. Second, in the first survey conducted just after the end of the first wave of COVID-19, respondents answered the satisfaction score at two points in time (before the spread of COVID-19 and just after the end of the first wave). The baseline assessment of the satisfaction score used the interviewee's recall scores when the pandemic had not yet occurred. Therefore, the satisfaction scores at baseline could be affected by recall bias. Third, we used individual data obtained from the Cabinet Office's Internet surveys. In Japan, many academic papers and government reports have utilized internet survey data from pre-registered monitors of web-based internet survey companies. However, respondents to internet surveys may have used the internet more frequently than non-respondents, and it cannot be denied that this may have affected the results of their responses. Finally, the research response rate was somewhat low, and whether there were any specific groups that have not responded more severely to the pandemic is unclear. Therefore, caution should be exercised when interpreting the results of this study. Further research based on the latest dataset with more long-term detailed information on respondents is required to examine the changes in daily life satisfaction among community-dwelling elderly under long-term stressful situations.

Author Contributions: Conceptualization, A.I.; methodology, A.I.; software, A.I.; formal analysis, A.I.; writing — original draft preparation, A.I.; writing-review and editing, E.I.; funding acquisition, A.I. All authors have read and agreed to the published version of the manuscript.

Funding: This research was funded by a Grant-in Aid for Scientific Research (C) [grant number 18K05865] from the Japan Society for the Promotion of Science (JSPS).

Institutional Review Board Statement: Ethical review and approval were not required for this study because we used the publicly available secondary data provided by the Cabinet Office of Japan under the conditions that (1) the individual data provided shall not be used to identify individual informants, (2) security management measures shall be taken for the provided data, and (3) the provided data shall be used only by the person who has applied for the data to the Cabinet Office of Japan, and shall not be provided again to a third party.

Informed Consent Statement: Informant consent was waived. This was because (1) the secondary data used was publicly available in such a manner that the dataset did not contain any personal information that could identify subjects, directly or through identifiers linked to the subjects, (2) internet surveys were conducted by the internet survey company on request of the Cabinet Office of Japan in compliance with Japanese domestic laws and regulations regarding the protection of personal information, and guidelines established by regulatory authorities.

Data Availability Statement: Individuals' data from the first and second internet surveys on "Changes in Daily Life Awareness and Behavior under the Influence of the New Coronavirus Infection" are publicly available on request to the Cabinet Office of Japan.

Acknowledgments: The authors would like to thank the Cabinet Office of Japan for providing us with the individuals' data from the first and second internet surveys on "Changes in Daily Life Awareness and Behavior under the Influence of the New Coronavirus Infection".

Conflicts of Interest: The authors declare no conflict of interest.

\section{References}

1. Giebel, C.; Lord, K.; Cooper, C.; Shenton, J.; Cannon, J.; Pulford, D.; Shaw, L.; Gaughan, A.; Tetlow, H.; Butchard, S.; et al. A UK survey of COVID-19 related social support closures and their effects on older people, people with dementia, and carers. Int. J. Geriatr. Psychiatry 2021, 36, 393-402. [CrossRef] [PubMed]

2. Lehtisalo, J.; Palmer, K.; Mangialasche, F.; Solomon, A.; Kivipelto, M.; Ngandu, T. Changes in Lifestyle, Behaviors, and Risk Factors for Cognitive Impairment in Older Persons During the First Wave of the Coronavirus Disease 2019 Pandemic in Finland: Results from the FINGER Study. Front. Psychiatry 2021, 12, 624125. [CrossRef] [PubMed] 
3. Carstensen, L.L.; Shavit, Y.Z.; Barnes, J.T. Age Advantages in Emotional Experience Persist Even Under Threat From the COVID-19 Pandemic. Psychol. Sci. 2020, 31, 1374-1385. [CrossRef] [PubMed]

4. Carson, J.; Prescott, J.; Allen, R.; McHugh, S. Winter is coming: Age and early psychological concomitants of the Covid-19 pandemic in England. J. Public Ment. Health 2020, 19, 221-230. [CrossRef]

5. $\quad$ Bidzan-Bluma, I.; Bidzan, M.; Jurek, P.; Bidzan, L.; Knietzsch, J.; Stueck, M.; Bidzan, M. A Polish and German Population Study of Quality of Life, Well-Being, and Life Satisfaction in Older Adults During the COVID-19 Pandemic. Front. Psychiatry 2020, 11, 585813. [CrossRef] [PubMed]

6. García-Fernández, L.; Romero-Ferreiro, V.; López-Roldán, P.D.; Padilla, S.; Rodriguez-Jimenez, R. Mental Health in Elderly Spanish People in Times of COVID-19 Outbreak. Am. J. Geriatr. Psychiatry 2020, 28, 1040-1045. [CrossRef] [PubMed]

7. Morales-Vives, F.; Dueñas, J.-M.; Vigil-Colet, A.; Camarero-Figuerola, M. Psychological Variables Related to Adaptation to the COVID-19 Lockdown in Spain. Front. Psychol. 2020, 11, 565634. [CrossRef] [PubMed]

8. Zach, S.; Zeev, A.; Ophir, M.; Eilat-Adar, S. Physical activity, resilience, emotions, moods, and weight control of older adults during the COVID-19 global crisis. Eur. Rev. Aging Phys. Act. 2021, 18, 5. [CrossRef] [PubMed]

9. Yamamoto, T.; Uchiumi, C.; Suzuki, N.; Yoshimoto, J.; Murillo-Rodriguez, E. The Psychological Impact of 'Mild Lockdown' in Japan during the COVID-19 Pandemic: A Nationwide Survey under a Declared State of Emergency. Int. J. Environ. Res. Public Health 2020, 17, 9382. [CrossRef] [PubMed]

10. Japan Starts COVID-19 Vaccinations for Health Workers. NIKKEI Asia (17 February 2021). Available online: https:/ / asia.nikkei com/Spotlight/Coronavirus/Japan-starts-COVID-19-vaccinations-for-health-workers (accessed on 13 July 2021).

11. COVID-19 Vaccines to Be Available to All under 65 in Japan at Same Time. The Japan Times (30 May 2021). Available online: https:/ / www.japantimes.co.jp/news/2021/05/30/national/science-health/covid-vaccines-available-under-65-japan/ (accessed on 13 July 2021).

12. Japan Starts Vaccinating People Age 18 and Older at State-Run Centers. The Japan Times (17 June 2021). Available online: https:/ / www.japantimes.co.jp/news/2021/06/17/national/vaccinations-18-plus/ (accessed on 13 July 2021).

13. Ministry of Health, Labour and Welfare. Outbreak Trend of New Coronavirus Infections in Japan (as of 18:00, 20 May 2020). Available online: https:/ /www.mhlw.go.jp/content/10906000/000716059.pdf (accessed on 15 March 2021).

14. Ueda, M.; Stickley, A.; Sueki, H.; Matsubayashi, T. Mental health status of the general population in Japan during the COVID -19 pandemic. Psychiatry Clin. Neurosci. 2020, 74, 505-506. [CrossRef] [PubMed]

15. Qiu, J.; Shen, B.; Zhao, M.; Wang, Z.; Xie, B.; Xu, Y. A nationwide survey of psychological distress among Chinese people in the COVID-19 epidemic: Implications and policy recommendations. Gen. Psychiatry 2020, 33, e100213. [CrossRef] [PubMed]

16. Nagata, A.; Yamagata, Z.; Nakamura, K.; Miyamura, T.; Asaka, A. Sex differences in subjective well-being and related factors in elderly people in the community aged 75 and over. Jpn. J. Geriatr. 1999, 36, 868-873, (In Japanese with English summary). [CrossRef] [PubMed]

17. Okamoto, H. [Effects of social activities on life satisfaction among the elderly: Four aspects in men and women]. Nihon Koshu Eisei Zasshi (Jpn. J. Public Health) 2008, 55, 388-395, (In Japanese with English summary).

18. Shishido, K. Difference between Men's Happiness and Women's Happiness in Later Life: An Analysis Based on JGSS Integrated Data 2000/2001. JGSS Research Series, No. 3. Available online: https://jgss.daishodai.ac.jp/english/research/monographs/ jgssm6/jgssm6_03.pdf (accessed on 15 July 2021). (In Japanese with English summary).

19. Yamada, M.; Kimura, Y.; Ishiyama, D.; Otobe, Y.; Suzuki, M.; Koyama, S.; Kikuchi, T.; Kusumi, H.; Arai, H. Effect of the COVID-19 Epidemic on Physical Activity in Community-Dwelling Older Adults in Japan: A Cross-Sectional Online Survey. J. Nutr. Health Aging 2020, 23, 1-3.

20. WHILL. Announcing the Results of a Survey on the Impact of Corona Damages on Senior Citizens' Outings and Social Participation. Available online: https://whill.inc/jp/news/28585 (accessed on 19 June 2021). (In Japanese).

21. Omron. A Survey of 1000 Elderly People Aged 65 and over on the Actual Situation of "with Corona". Available online: https:/ / www.healthcare.omron.co.jp/corp/news/2020/0713.html (accessed on 19 June 2021). (In Japanese).

22. Misawa, J.; Kondo, K. Social factors relating to depression among older people in Japan: Analysis of longitudinal panel data from the AGES project. Aging Ment. Health 2018, 23, 1423-1432. [CrossRef] [PubMed]

23. Saito, J.; Kondo, N.; Saito, M.; Takagi, D.; Tani, Y.; Haseda, M.; Tabuchi, T.; Kondo, K. Exploring 2.5-year trajectories of functional decline in older adults by applying a growth mixture model and frequency of outings as predictor: A 2010-2013 JAGES longitudinal survey. J. Epidemiol. 2019, 29, 65-72. [CrossRef]

24. Hikichi, H.; Kondo, K.; Takeda, T.; Kawachi, I. Social interaction and cognitive decline: Results of a 7-year community intervention. Alzheimer's Dement. Transl. Res. Clin. Interv. 2017, 3, 23-32. [CrossRef] [PubMed]

25. Saito, T.; Murata, C.; Saito, M.; Takeda, T.; Kondo, K. Influence of social relationship domains and their combinations on incident dementia: A prospective cohort study. J. Epidemiol. Community Health 2018, 72, 7-12. [CrossRef] [PubMed] 